\title{
Thermodynamic analysis of a Carbon Carrier Cycle (CCC) for low temperature heat recovery
}

\author{
Diego Micheli, Mauro Reini, and Rodolfo Taccani* \\ Department of Engineering and Architecture, University of Trieste, Italy
}

\begin{abstract}
The aim of the paper is to study the thermodynamic behavior of a non-conventional power cycle, named Carbon Carrier Cycle (CCC), which is expected to obtain interesting performance with low temperature heat source. The CCC may be regarded as derived from an absorption machine, where an expander replaces the condenser, the throttling valve and the evaporator. The working fluid is a mixture of $\mathrm{CO}_{2}$ and a proper absorber. In the paper, the thermodynamic model of this kind of cycles is described, and the results obtained considering Acetone as the absorber are discussed. A first performance comparison is then conducted with a more conventional Organic Rankine Cycle (ORC).
\end{abstract}

\section{Introduction}

In recent years, interest for the total efficiency of complex energy systems has grown considerably. In this perspective, the recovery of waste heat output flows may be quantitatively important and CHP is a wellknown and widely used approach. On the other hand, there are a lot of situations where the low temperature heat cannot be usefully consumed. In these cases, the total efficiency of the system may be improved by adopting a bottom power cycle, which uses the low temperature heat as the input for producing some additional power.

An ORC is a possible solution, adopting a proper working fluid. The conversion efficiency of such a bottom cycles is necessary low. If the temperature of the recovered heat and that of the cooling medium in the condenser are considered to be $90^{\circ} \mathrm{C}$ and $25^{\circ} \mathrm{C}$, respectively, the maximum theoretical efficiency (i.e. the Carnot efficiency) is less than $18 \%$, therefore the expected actual efficiency is much lower in any case.

The aim of the paper is to evaluate the behavior and the performance expected for a non-conventional kind of cycle, named Carbon Carrier Cycle (CCC) [1]. A CCC may be regarded as derived from an absorption machine, where an expander replaces condenser, throttling valve and evaporator. The working fluid in the expander is pure $\mathrm{CO}_{2}$, or a mixture rich of $\mathrm{CO}_{2}$.
The CCC may be regarded as a particular case of Absorption Power Cycle (APC), the most famous of which is certainly the Kalina Cycle [2]. These power cycles are characterized by the adoption of a mixture as working fluid, instead of a pure substance, which passes through different concentrations during the energy conversion process, so that absorption-desorption processes are necessary involved.

In a $\mathrm{CCC}$, the $\mathrm{CO}_{2}$ is absorbed into a liquid phase at an equilibrium temperature defined by the cooling fluid and it is released at higher pressure at an equilibrium temperature defined by the thermal level of the recovered heat. In this arrangement, the expansion in the turbine or in the volumetric expander can be extended to the pressure inside the absorber, which corresponds to the equilibrium condition of the mixture $\left(\mathrm{CO}_{2}\right.$ plus the absorbent), not to the phase change equilibrium pressure of the expander working fluid alone. This feature may positively affect the efficiency of the cycle, with respect to more conventional solutions.

A review of different APC can be found in Novotny et al. [3], [4]. In the CCC the working fluid is a mixture of $\mathrm{CO}_{2}$, as previously said, and some organic compound, like ammines or ketones [5]. In this paper in particular, a binary mixture of Acetone and $\mathrm{CO}_{2}$ is considered, because the former can be mixed in very variable percentages, making it possible to analyze the use of different mixtures from the point of view of the $\mathrm{CO}_{2}$ content.

\footnotetext{
*Corresponding author: taccani@ units.it
} 
In the paper the thermodynamic model of a CCC is described, and the results obtained varying the main design parameters are discussed, for different temperature levels of the recovered heat. A first performance comparison is then conducted with an ORC using Acetone as working fluid.

\section{Model of the cycles}

In the following, the model of the CCC is described in some details, together with a brief presentation of the ORC model, introduced for performance comparison. They are both simple thermodynamic models, based on the energy balance equation of each component and on the assumption of suitable constant efficiencies values for pumps and expanders. Heat and pressure losses are neglected.

To carry on the comparison between CCC and ORC, common temperature ranges are considered for the heat source and the heat sink, neglecting the parasitic consumptions required for moving the hot and cooling fluids trough the necessary heat exchangers. In this way, the comparison results independent by the specific heat recovery application. In fact, the parasitic consumption may be very different if the low temperature power cycle is applied for the heat recovery from an on board ICE for ship propulsion, with a see water cooled condenser, instead of to the power production of a concentrated solar system, with an air cooled condenser.

The cycle working fluid temperature in the correspondence of the heat sink is considered in the range $15-45^{\circ} \mathrm{C}$, whilst those in the correspondence of the heat source varies in the range $90-150^{\circ} \mathrm{C}$. The design efficiencies of pumps and expanders have been regarded as not affected by those temperature ranges and are equal to:

- $\quad$ pump isentropic efficiency: 0.8;

- expander isentropic efficiency: 0.8;

- mechanical efficiencies: 0.9;

- electric efficiency: 0.95 .

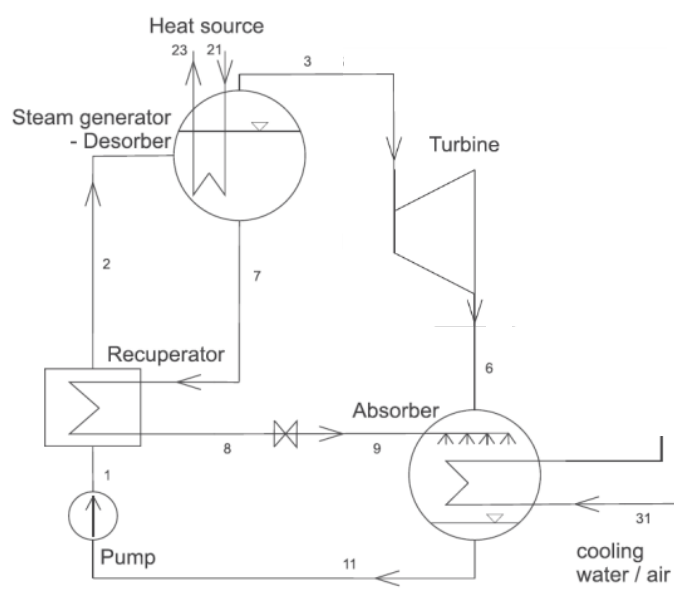

Fig. 1. Scheme of the CCC considered in the analysis.

\subsection{The model of the CCC}

Fig.1 shows the scheme of the CCC chosen for the analysis. A liquid mixture at the maximum concentration of solute is pumped to the vapour generator, after being heated in a recuperator. The vapour generator is a desorber, which can be modelled in different ways as better discussed in the following. The desorber generates a vapour flow at high solute concentration and a liquid flow at low solute concentration. The first passes through an expander generating mechanical-electrical power. The second is cooled in the recuperator before being laminated in a pulveriser. The two flows mix at low temperature and pressure in the absorber, and the resulting liquid mixture is sent to the pump suction, thus closing the cycle. Heat is exchanged with the heat source in the desorber and with the heat sink in the absorber.

The main design variables are the temperature of the vapour flow exiting the desorber, $\mathrm{T}_{\mathrm{vap}}$, and the temperature of the saturated liquid in the absorber, indicated in the following as $\mathrm{T}_{\text {ass, }}$ which stay in thermodynamic analogy with the condensation temperature of the best-known Rankine cycle.

$\mathrm{T}_{\text {vap }}$ is a function of the desorber pressure and of the degree of completion of the evaporation of the mixed fluid entering the desorber. Such a degree is defined as $\left(\mathrm{T}_{\mathrm{vap}}-\mathrm{T}_{\mathrm{sl}}\right) /\left(\mathrm{T}_{\mathrm{sv}}-\mathrm{T}_{\mathrm{sl}}\right)$, where $\mathrm{T}_{\mathrm{sl}}$ and $\mathrm{T}_{\mathrm{sv}}$ are the saturated liquid and saturated vapour temperatures, respectively, of the mixed fluid at the desorber pressure.

$\mathrm{T}_{\text {ass }}$ is a function of the absorber pressure and of the mixed fluid composition, i.e. of the molar fraction of the solvent or of the solute.

As previously said, the desorber may be designed in different ways. The basic design may be regarded as directly derived by the standard arrangement adopted for absorption cooling cycles. In this arrangement, the vapour-liquid phase separation is obtained with a single step in a drum, at the temperature $\mathrm{T}_{\text {vap }}$ and at the desorber pressure.

With this arrangement, at high degrees of completion of the evaporation, i.e. at high $T_{\text {vap values, }}$ correspond the production of vapour in saturated condition with a poor solute concentration. Such a concentration could be successively incremented with a vapour rectification process, but the final mass flow rate of solute in the expander it would still be very low. On the contrary, at low $\mathrm{T}_{\text {vap }}$ values correspond the production of vapour in saturated condition with a high solute concentration but, again, the final mass flow rate of solute in the expander would be very low.

A different arrangement is considered in this paper, where the liquid mixture entering the desorber is continuously heated in counter-current with the heat source thermal vector, starting from the temperature $\mathrm{T}_{\mathrm{sl}}$ up to the temperature $T_{\text {vap }}$, as shown in the scheme of Fig. 2 and in the equilibrium diagram of Fig.3. The phase separation starts at the points indicated in Fig. 3 by the lower temperature markers (blue circle for the liquid and red circle for the vapour phase) with the initial production of high solute concentration vapour, and proceeds up to the higher temperature markers, with a high level of completion of the evaporation process. In 
the meantime, the progressively produced vapour is continuously collected, and superheated at the temperature $T_{\text {vap. }}$. The result is a final high mass flow rate of solute rich and superheated vapour, at the thermodynamic condition shown with a $\mathrm{x}$ blue marker in Fig.3.

The proposed arrangement is, in the authors' opinion, in agreement with the scheme found in a patent of the Climeon Company [6], and reported in Fig.4.

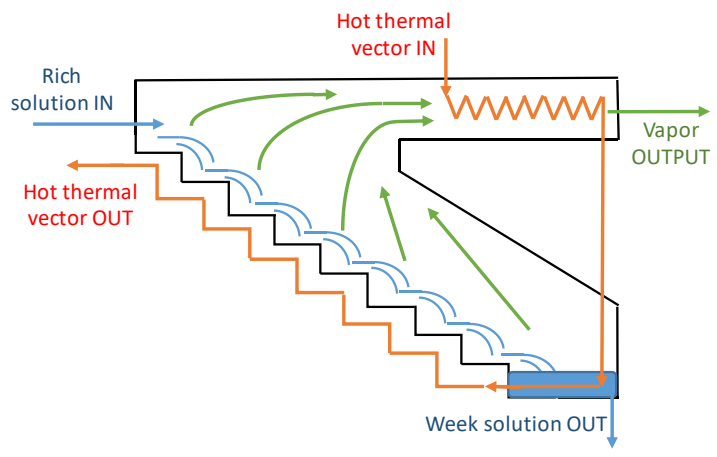

Fig. 2. Scheme of the desorber considered in the analysis.

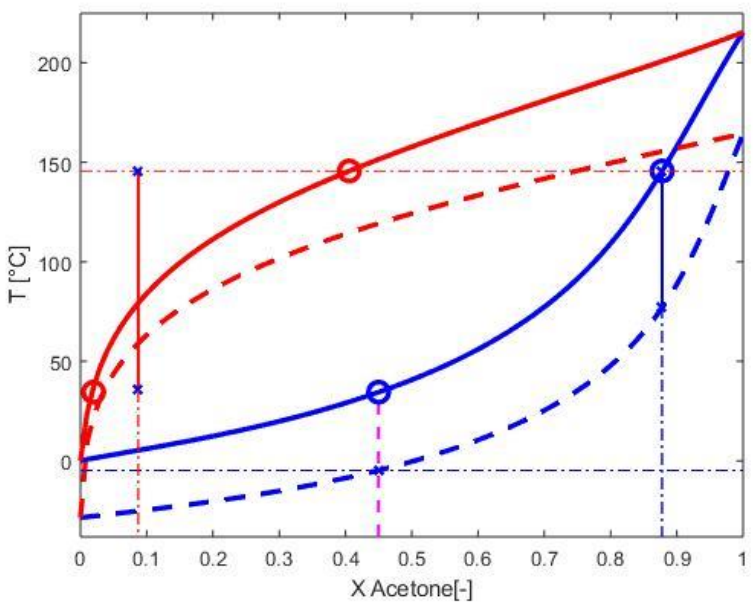

Fig. 3. Equilibrium diagram of the binary mixture Acetone + $\mathrm{CO}_{2}$, considering $\mathrm{P}_{\text {ass }}=15$ bar, $\mathrm{P}_{\text {vap }}=35$ bar.

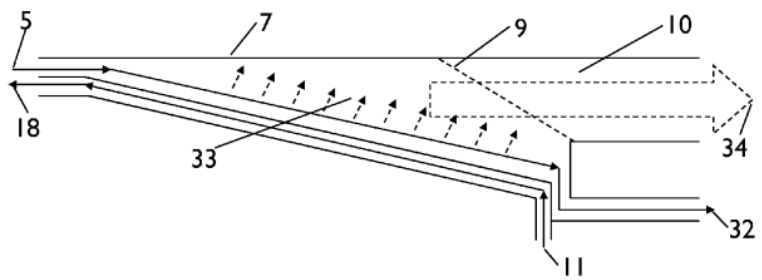

Fig. 4. Scheme of the desorber reported in a patent of the Climeon Company [6].

In the thermodynamic model of the CCC cycle, the calculation has been arranged, according to the scheme of Fig.5, as a series of phase separators operating at increasing temperature. The division into 40 steps proved to be sufficient to simulate the real continuous process.

The considered working fluids are binary mixtures of Acetone as absorber (solvent) and $\mathrm{CO}_{2}$ as solute, at various molar concentrations, $\mathrm{X}_{\mathrm{Ac}}$ and $\mathrm{X}_{\mathrm{CO} 2}$, where is obviously $\mathrm{X}_{\mathrm{CO} 2}=1-\mathrm{X}_{\mathrm{Ac}}$.
The thermodynamic properties of the mixtures and the enthalpy of mixing values, in every significant point of the cycle, have been obtained by means of REFPROP. The calculations employ a model that applies mixing rules to the Helmholtz energy of the components. The departure function from ideal mixing is consistent with the GERG model [7].

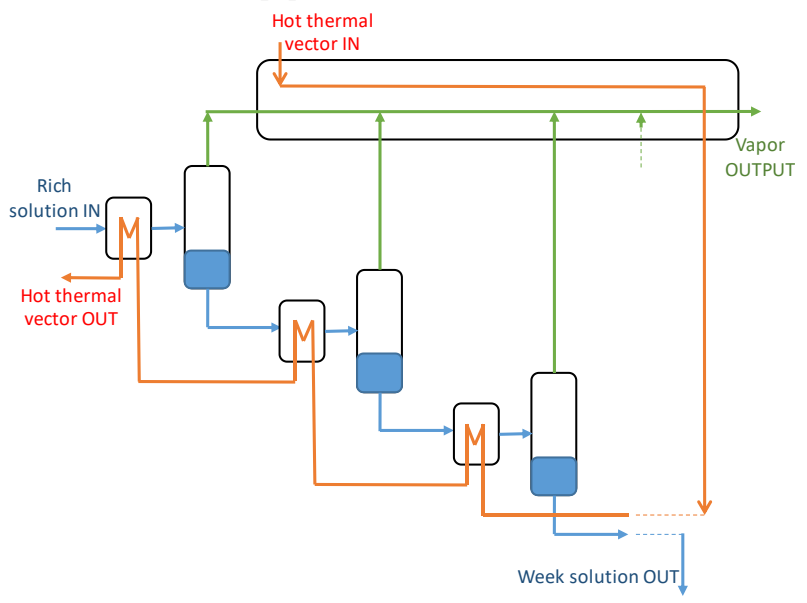

Fig. 5. Scheme of the discrete-block model of the desorber considered in the calculation.

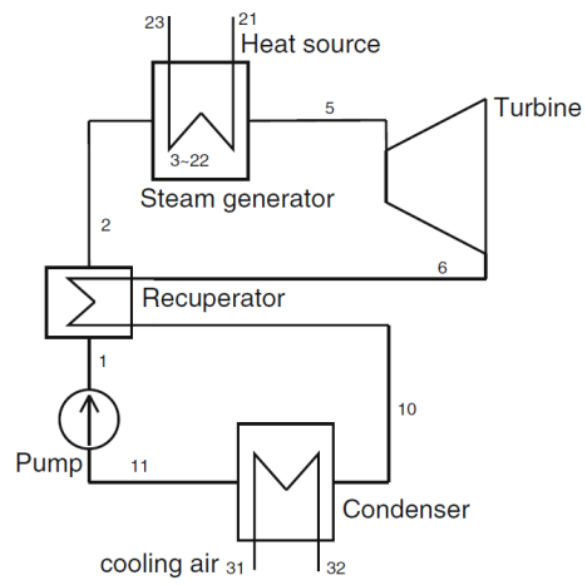

Fig. 6. Scheme of the simple single pressure level ORC.

\subsection{The model of the ORC}

The simulated ORC is a simple single pressure level cycle, as reported in Fig.6. The main design variables, chosen in order to facilitate the comparison with the CCC cycle with reference to the same heat and sink sources, are the evaporation temperature $\mathrm{T}_{\text {vap }}$ and the condensing temperature $\mathrm{T}_{\text {con }}$. The possible working fluids must be pure substances, having thermodynamic properties compatible with the design variables. In the present analysis, the working fluid is Acetone, which is the solvent of the binary mixture taken in to account for the CCC cycle. As shown in the T-s diagram of Fig. 7, the minimum condensing temperature of $15^{\circ} \mathrm{C}$ correspond to a pressure of 0.2 bar while the maximum vapour temperature of $150^{\circ} \mathrm{C}$ correspond to a pressure of 13 bar. The critical point is at $235^{\circ} \mathrm{C}$ and 47 bar. The saturated vapour line is almost isentropic but, at the lowest pressure, it assumes a wet fluid behavior, for which a small superheating degree of $5^{\circ} \mathrm{C}$ has been 
assumed to avoid excessive condensation at the expander exit. The cycle can be simple or regenerative. In the last case, the effectiveness of the regenerative heat exchanger is equal to 0.85 . The properties of Acetone are calculated with REFPROP.

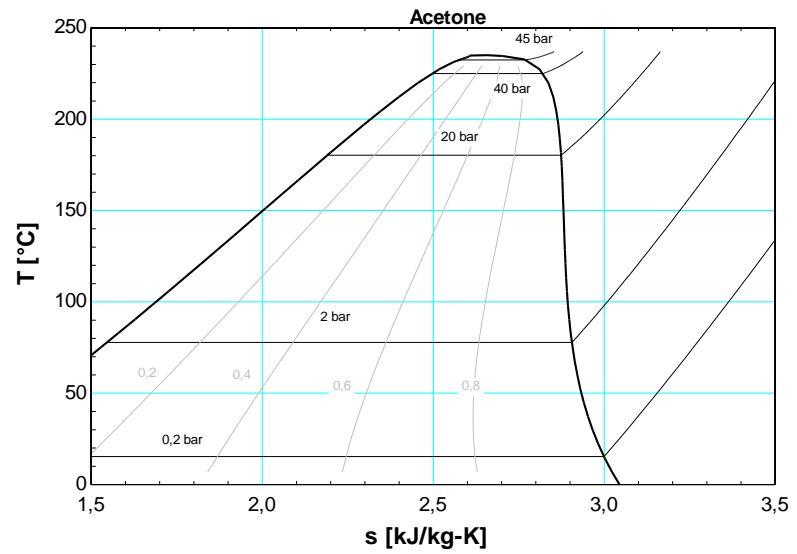

Fig. 7. T-s diagram of pure Acetone.

\section{Results}

The equilibrium diagram of the just cited Fig.3, the T-s diagram of Fig. 8 and the P-T one of Fig.9 are useful to understand the operating characteristics of the CCC cycle, obtained with the model described in the previous paragraph. The values assumed in this example for the main variables are:

$$
\begin{array}{ll}
- & \mathrm{X}_{\mathrm{Ac}}=0.45 \\
- & \mathrm{P}_{\mathrm{ass}}=15 \mathrm{bar} \\
- & \mathrm{P}_{\mathrm{vap}}=35 \mathrm{bar} \\
- & \left(\mathrm{T}_{\mathrm{vap}}-\mathrm{T}_{\mathrm{sl}}\right) /\left(\mathrm{T}_{\mathrm{sv}}-\mathrm{T}_{\mathrm{sl}}\right)=0.95
\end{array}
$$

The corresponding design temperatures are $\mathrm{T}_{\text {ass }}=$ $4.8^{\circ} \mathrm{C}$ and $\mathrm{T}_{\mathrm{vap}}=145.6^{\circ} \mathrm{C}$. The net efficiency of the cycle is 0.14 .

As reported in Fig.3, the liquid mixture with $\mathrm{X}_{\mathrm{Ac}}=0.45$ pumped into the desorber is splitted in a vapour flow with $\mathrm{X}_{\mathrm{Ac}}=0.087$ and in a liquid flow with $\mathrm{X}_{\mathrm{Ac}}=0.878$. In the figure, the red and blue vertical lines show the evolution along the cycle of the vapour and liquid flows, respectively, while the magenta line refers to the pumped mixture (colours have the same meaning also in Fig.8 and Fig.9). The resulting mass flow rate distribution is $48.63 \%$ vapour and $51.37 \%$ liquid. Then, as can be seen in Fig.8 and Fig.9, the vapour flow expands adiabatically while the pumped mixture cools the liquid flow. The dotted lines in these figures represent schematically the desorbing and adsorbing processes. In particular, the magenta dash-point line in Fig. 8 shows, in a simplified way, the progressive evaporation in the desorber described in the previous paragraph.

Again, in Fig. 8 the green curves are the saturated liquid and vapour lines of the mixtures in the various phases of the cycle while the black lines refer to the pure carbon dioxide.

The pressures in the absorber and in the desorber of this example have been selected because they could allow operating in the chosen temperature range of heat source and sinking, as can be appreciated in Fig.3. The maximum net efficiency is achieved, however, for the cited values of $X_{A c}$ and $\left(T_{\text {vap }}-T_{s l}\right) /\left(T_{s v}-T_{s l}\right)$, to which correspond the previously seen high value of $\mathrm{T}_{\text {vap }}$ and low value of $\mathrm{T}_{\text {ass, }}$, the last one, in particular, completely out of the desired range.

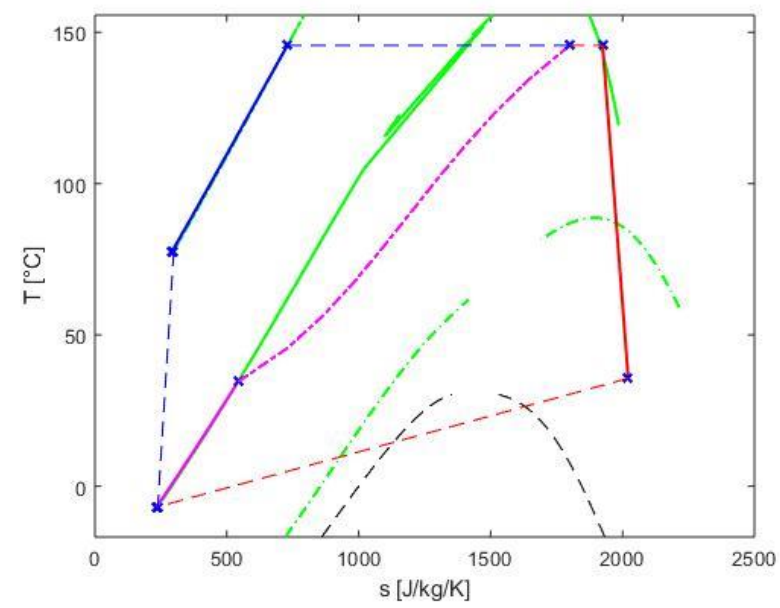

Fig. 8. $T$-s diagram of the $C C C-P_{a s s}=15$ bar, $P_{v a p}=35$ bar.

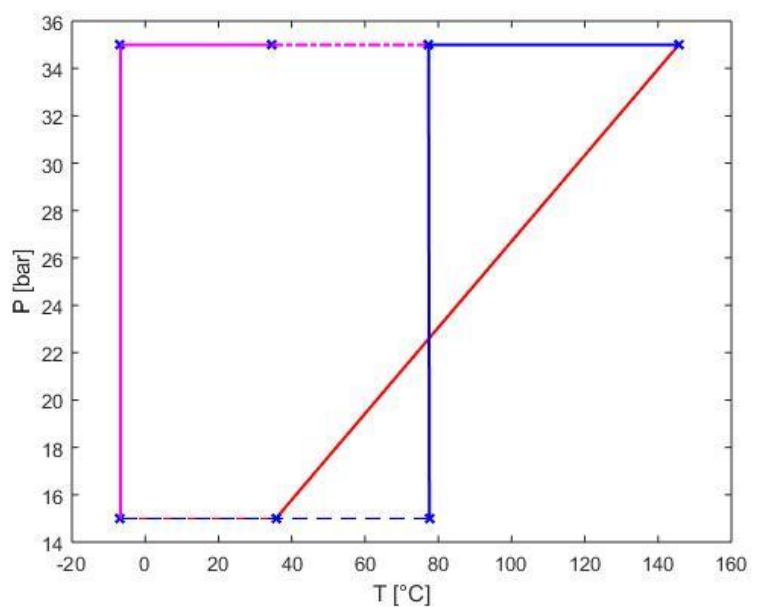

Fig. 9. $P-T$ diagram of the CCC- $P_{\text {ass }}=15$ bar, $P_{\text {vap }}=35$ bar.

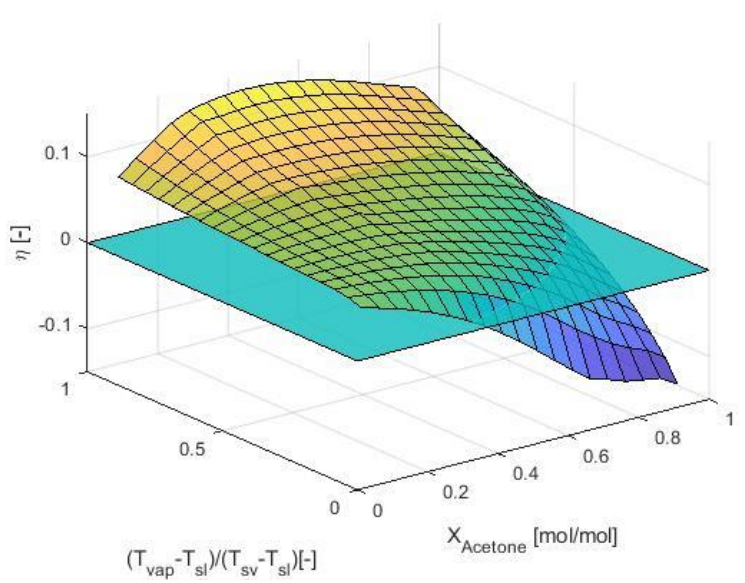

Fig. 10. Net efficiency of the $C C C-P_{a s s}=15$ bar, $P_{v a p}=35$ bar.

The variation of the net efficiency of the cycle with $\mathrm{X}_{\mathrm{Ac}}$ and $\left(\mathrm{T}_{\mathrm{vap}}-\mathrm{T}_{\mathrm{sl}}\right) /\left(\mathrm{T}_{\mathrm{sv}}-\mathrm{T}_{\mathrm{sl}}\right)$ at the considered values of $\mathrm{P}_{\text {ass }}=15$ bar and $\mathrm{P}_{\mathrm{vap}}=35$ bar is shown in the surface diagram of Fig.10. With high values of $\mathrm{X}_{\mathrm{Ac}}$ and low 
values $\left(\mathrm{T}_{\mathrm{vap}}-\mathrm{T}_{\mathrm{sl}}\right) /\left(\mathrm{T}_{\mathrm{sv}}-\mathrm{T}_{\mathrm{sl}}\right)$ the adsorbed power of the pump is greater than the positive power produced by the expander and the efficiency falls below zero. The maximum efficiency is reached at the maximum obtainable values of $\left(\mathrm{T}_{\mathrm{vap}}-\mathrm{T}_{\mathrm{sl}}\right) /\left(\mathrm{T}_{\mathrm{sv}}-\mathrm{T}_{\mathrm{sl}}\right)$ and for intermediate values of $\mathrm{X}_{\mathrm{Ac}}$, that corresponds to the optimal balance between the pump and the expander flows, as shown in Fig.11.

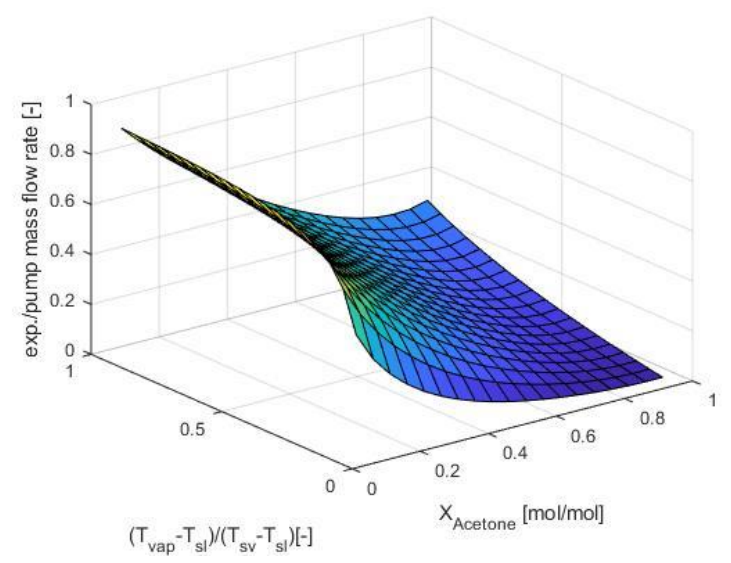

Fig. 11. Flow rate ratio in the expander and in the pump of the $C C C-P_{\text {ass }}=15$ bar, $P_{\text {vap }}=35$ bar.

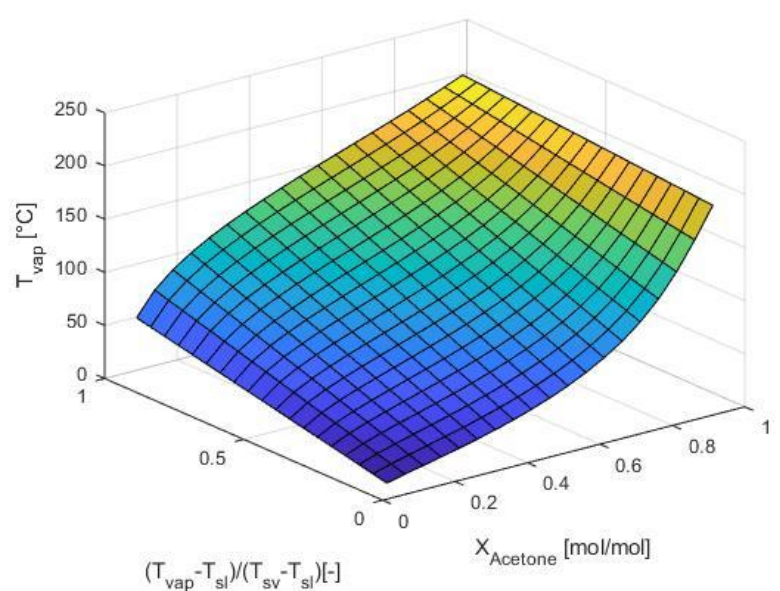

Fig. 12. $T_{\text {vap }}$ of the $C C C-P_{\text {ass }}=15$ bar, $P_{\text {vap }}=35$ bar.

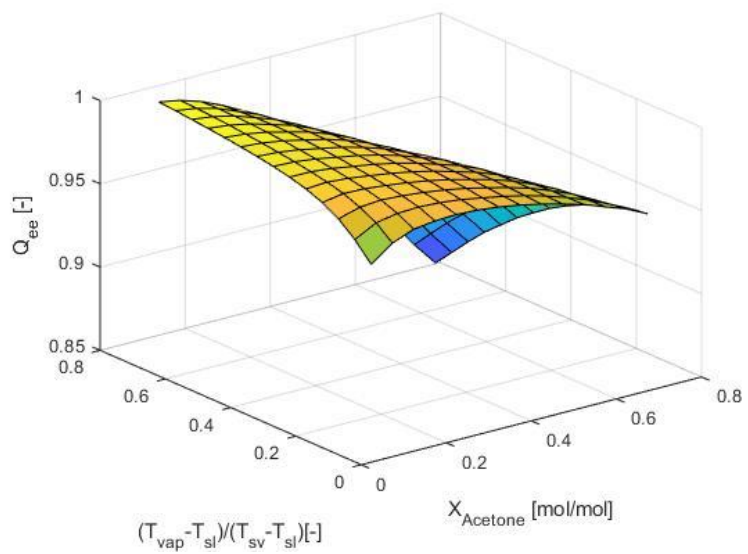

Fig. 13. Vapor quality at the expander exit $\left(Q_{e e}\right)$ of the CCC $\mathrm{P}_{\mathrm{ass}}=15$ bar, $\mathrm{P}_{\mathrm{vap}}=35$ bar.

The corresponding values of $\mathrm{T}_{\text {vap }}$ are reported in Fig.12, where it can be seen that values compatible with the chosen lower bound temperatures of the heat source are obtainable only at very low $\mathrm{X}_{\mathrm{Ac}}$ values, with a sensible but still acceptable reduction of efficiency. The vapour quality at the expander exit, given in Fig.13, is always sufficiently high to avoid operating problems with almost all kinds of expander.

Obviously, the maximum efficiency increases with higher $\mathrm{P}_{\text {vap }}$ values and lower $\mathrm{P}_{\text {ass }}$ values. Fig. 14 shows the results obtained varying $\mathrm{P}_{\text {ass }}$ from 0.2 bar to 15 bar and $P_{\text {vap }}$ from 2 bar to 45 bar. Figs. 15 and 16 report the corresponding values of $\mathrm{T}_{\text {vap }}$ and $\mathrm{T}_{\text {ass. }}$.

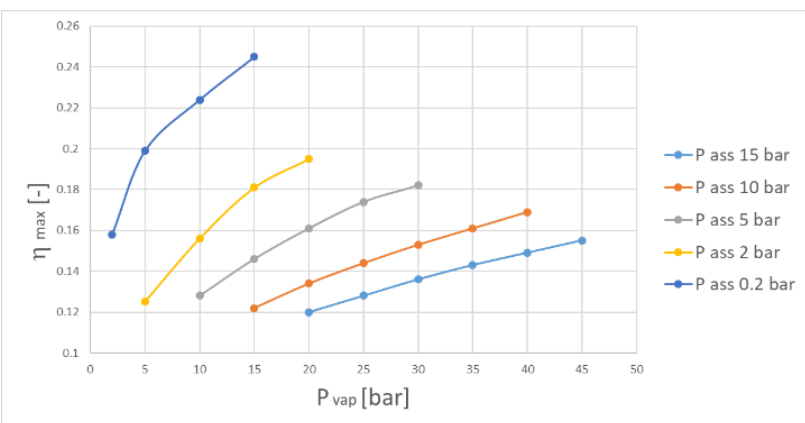

Fig.14. Maximum efficiency obtained by the CCC vs. $\mathrm{P}_{\text {vap}}$, using $P_{\text {ass }}$ as a parameter.

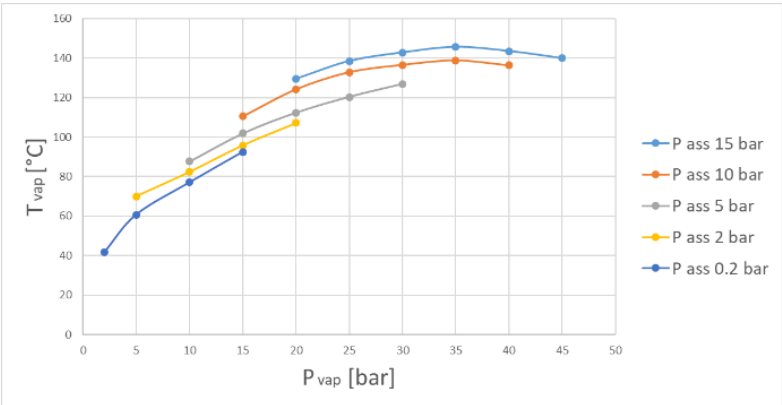

Fig.15. $T_{\text {vap }}$ of maximum efficiency for the CCC vs. $P_{\text {vap }}$, using $P_{\text {ass }}$ as a parameter.

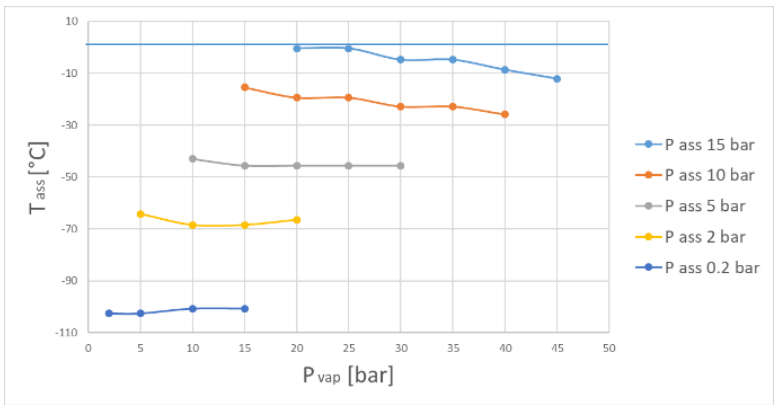

Fig.16. $\mathrm{T}_{\text {ass }}$ of maximum efficiency for the $\mathrm{CCC}$ vs. $\mathrm{P}_{\text {vap}}$, using $\mathrm{P}_{\text {ass }}$ as a parameter.

The curves of $\mathrm{T}_{\text {vap }}$ show that, with an accurate choice of the pressures, it is possible to reach good efficiencies at almost all the considered range of the heat source temperatures, but such a good result is also due to the corresponding optimal values of $\mathrm{T}_{\text {ass, }}$, which falls in the range of cold or criogenic temperatures.

The most significant limit to the use of the CCC cycle considered in this analysis is then the very low temperature in the absorber, which do not allow considering the environment as the heat sink.

The discussion of this topic can be carried on with reference to the Fig.17, which reports the equilibrium temperatures of the saturated liquid of the Acetone- $\mathrm{CO}_{2}$ 
mixtures at absorber pressures in the range $0.2-40$ bar. The two vertical blue dotted lines indicate the values of $\mathrm{X}_{\mathrm{Ac}}$ corresponding to the best efficiency conditions in the various considered cycle arrangements, while the two horizontal red dotted lines indicate the range of ambient temperature between $15^{\circ} \mathrm{C}$ and $25^{\circ} \mathrm{C}$. It can be observed that for operating with $\mathrm{T}_{\text {ass }}$ in the ambient range it is necessary to choose $\mathrm{X}_{\mathrm{Ac}}$ values higher than that of the optimal range, and the higher the lower is the absorber pressure.

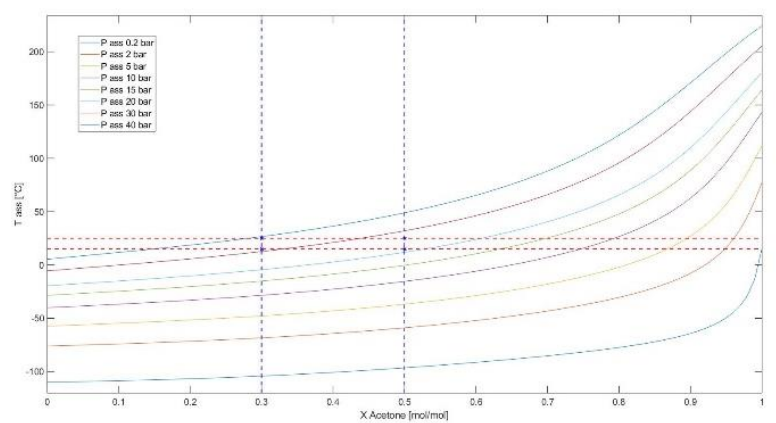

Fig.17. Equilibrium temperatures of the saturated liquid of the Acetone- $\mathrm{CO}_{2}$ mixtures vs. the absorber pressures.

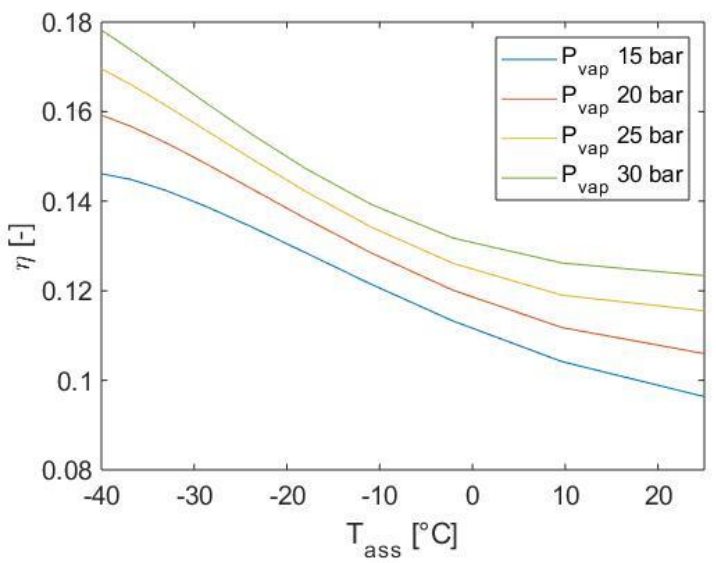

Fig.18. Efficiency of the CCC vs. $T_{\text {ass, }}$ using $P_{\text {vap }}$ as a parameter and for $\mathrm{P}_{\text {ass }}=5$ bar.

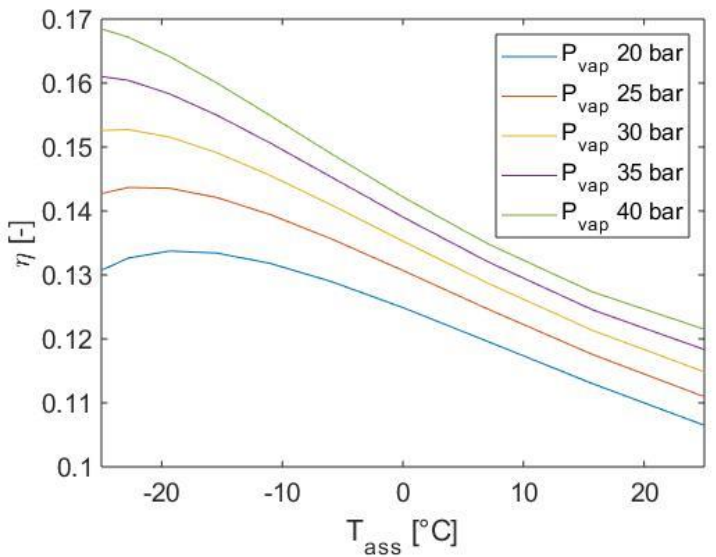

Fig.19. Efficiency of the CCC vs. $T_{\text {ass, }}$ using $P_{\text {vap }}$ as a parameter and for $\mathrm{P}_{\text {ass }}=10 \mathrm{bar}$.

The corresponding reduction of efficiency is visible in Figs.18-20 as a function of $\mathrm{T}_{\text {ass }}$ and $\mathrm{P}_{\text {vap }}$, for $\mathrm{P}_{\text {ass }}$ values of 5,10 and 15 bar and $\mathrm{T}_{\text {vap }}$ resulting by fixing $\left(\mathrm{T}_{\text {vap}}{ }^{-}\right.$
$\left.\mathrm{T}_{\mathrm{sl}}\right) /\left(\mathrm{T}_{\mathrm{sv}}-\mathrm{T}_{\mathrm{sl}}\right)=0.95$, close to the optimal value for maximum efficiency, as shown in Fig. 10. As a whole, it can be concluded that, although the reduction in efficiency is quite high, the results could be still acceptable.

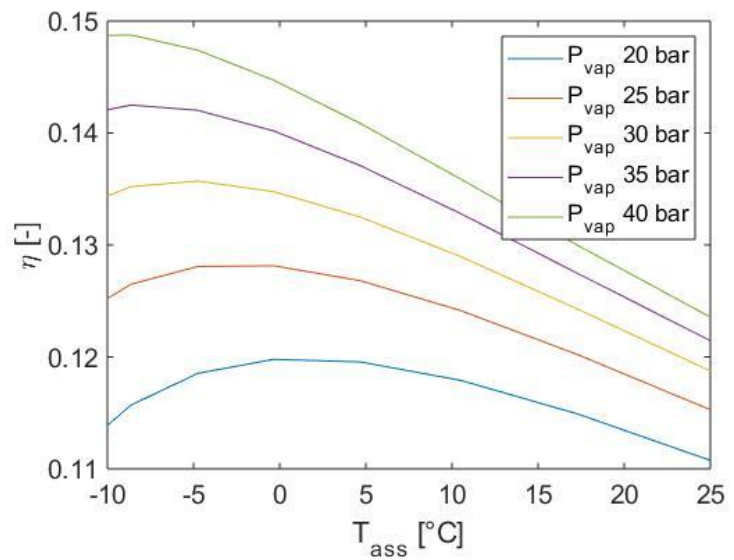

Fig.20. Efficiency of the $C C C$ vs. $T_{\text {ass, }}$ using $P_{\text {vap }}$ as a parameter and for $\mathrm{P}_{\text {ass }}=15 \mathrm{bar}$.

The net efficiency values obtained with the ORC model, where pure Acetone is considered as working fluid, are shown in Fig.21 as a function of the superheated vapor temperature $T_{\text {sh }}$, equal to $T_{\text {vap }}+5^{\circ} \mathrm{C}$ and variable from $90^{\circ} \mathrm{C}$ to $150^{\circ} \mathrm{C}$, for three values of $\mathrm{T}_{\text {con, }}$, i.e. 15,20 and $25^{\circ} \mathrm{C}$.

Only non-recuperated cycles are considered, because the wet characteristic of Acetone implies that a very poor internal regeneration effect could be obtained in the considered temperature range.

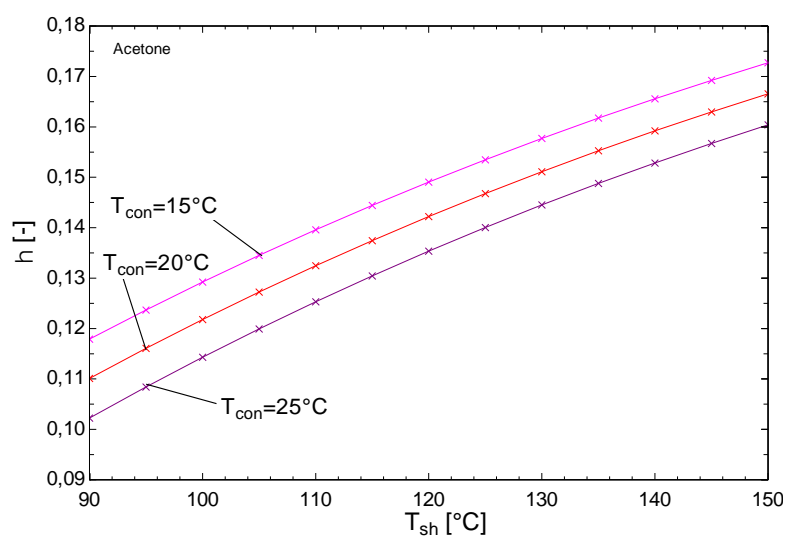

Fig.21. Efficiency of the $\mathrm{ORC}$ vs. $\mathrm{T}_{\mathrm{sh}}$, using $\mathrm{T}_{\text {con }}$ as a parameter.

By comparing these values with those discussed for the CCC, it is observed that, while the maximum values are comparable, those obtainable with the same minimum cycle temperature are always higher in the case of the ORC.

These results are not in accordance with what is stated in the technical documentation of groups such as those produced by Climeon, which refer to the patent [6], but the available technical information is limited, avoiding to mention the composition of the mixture, apart from the presence in it of $\mathrm{CO}_{2}$, and the details of the absorption and desorption processes. 


\section{CONCLUSIONS}

The modelization of an Acetone- $\mathrm{CO}_{2}$ cycle, which is a possible realization of a generic $\mathrm{CCC}$, has allowed to evaluate the influence on the cycle performance of the most important thermodynamic design variables and related constraints.

While the validity of the obtained quantitative results is limited to the choices made in the definition of the model, in particular to the choice of the solvent, the mutual qualitative influence of the variables on the performance can be extended to a wider range of cases, to be explored in the continuation of the research.

The main thermodynamic limit seems to be the low temperature required in the absorber to reach the maximum efficiencies, due to the correlations amongst mixture composition, absorber pressure, composition and mass flow rate of the solute rich vapor flow in the expander.

These features could make it interesting to study the adoption of the considered cycle in applications of WHR where the heat sink has temperature lower than the environmental one, as in the case of the regasification of liquefied gases.

\section{References}

1. Zhang X, He M, Zhang Y., A review of research on the Kalina cycle, Renewable and sustainable energy reviews, 16, 7, 2012, 5309-5318.

2. Vaclav Novotny, Michal Kolovratnik, Absorption power cycles for low-temperature heat sources using aqueous salt solutions as working fluids, Int. J. Energy Res., 2017, 41, 952-975.

3. Vaclav Novotny, Monika Vitvarova, Michal Kolovratnik, Absorption Power Cycles with Various Working Fluids for Exergy-Efficient LowTemperature Waste Heat Recovery, in The Role of Exergy in Energy and the Environment, S Nizetic and A Papadopoulos Editors, Springer 2018.

4. Thomas Robbins, Srinivas Garimella, Low-Grade Waste Heat Recovery for Power Production using an Absorption-Rankine Cycle, Proceeding of the International Refrigeration and Air Conditioning Conference at Purdue, July 12-15, 2010.

5. Climeon, Energy generation from waste heat using the Carbon Carrier thermodynamic Cycle, Patent $n^{\circ}$ US20160201521A1, 2006.

6. Ruben Havsed, A Modular and Vacuum Based ORC for Low Temperature Geothermal Power, GRC Transactions, Vol. 42, 2018.

7. Kunz O., Wagner W., The GERG-2008 Wide-Range Equation of State for Natural Gases and Other Mixtures: An Expansion of GERG-2004, J. of Chem. Eng. Data, vol. 57, n. 11, pp. 3032-3091, 2012. 